Artigo

\title{
A constituição de si: uma cartografia das subjetividades no devir professor de matemática dos Anos Iniciais do Ensino Fundamental
}

\author{
The constitution of the self: a cartography of subjectivities in the mathematics teacher of \\ the Early Years of Elementary School
}

\section{La constitucióndelyo: una cartografía de subjetividades enelprofesor de matemáticas de losprimerosaños de laescuela primaria}

\author{
Graciela Coelho Andrade de Souza ${ }^{1}$ \\ (D) [0000-0003-4982-8784] \\ Simone Moura Queiroz ${ }^{2}$ \\ iD [0000-0002-3878-4619]
}

\begin{abstract}
Resumo
Este trabalho apresenta um recorte das discussões e observações de campo realizadas para produção de dados da dissertação de mestrado "ALICE NO PAÍS DA DIFERENÇA: Uma aventura pelo devir professor de matemática dos Anos Iniciais do Ensino Fundamental". O qual teve por objetivo principal compreender as subjetividades presentes no devir professor de matemática dos Anos Iniciais do Ensino Fundamental. Um estudo decorrente do método da cartografia das subjetividades, realizado durante a pesquisa de campo com professores de uma escola pública de Jaboatão dos Guararapes - PE. Embasado na filosofia da diferença de Deleuze e na perspectiva de sujeito e sociedade defendida por Foucault para pensar o professor e suas subjetividades. Os resultados encontrados desvelam o professor enquanto sujeito composto de subjetividades, onde em um emaranhado de marcas, afetos e desejos resultantes do trajeto antropológico, movimentos e devir, o que impacta na constituição de si, legitimando as singularidades presentes no processo de ensino e aprendizagem da matemática.
\end{abstract}

Palavras-chaves: Cartografia. Devir. Filosofia da diferença. Formação. Matemática. Subjetividade.

\begin{abstract}
This work presents an excerpt of the discussions and field observations carried out for the production of data from the master's dissertation "ALICE IN THE COUNTRY OF DIFFERENCE: An adventure for the mathematics teacher of the Early Years of Elementary School". The main objective of which was to understand the subjectivities present in the mathematics teacher of the Early Years of Elementary School. A study resulting from the subjectivity mapping method, carried out during field research with teachers from a public school in Jaboatão dos Guararapes - PE. Based on Deleuze's philosophy of difference and on the perspective of subject and society defended by Foucault to think about the teacher and his subjectivities. The results found reveal the teacher as a subject composed of subjectivities, where in a tangle of marks, affections and desires resulting from the anthropological trajectory, movements and becoming, which impacts on the constitution of himself legitimizing the singularities present in the mathematical teaching and learning process.
\end{abstract}

\footnotetext{
1 gracinhasud19@hotmail.com, Mestra em Educação em Ciências e Matemática (UFPE), Coordenadora, Secretaria de Educação de Pernambuco, Recife/PE/Brasil.

2 simonemq35@gmail.com, Doutora em Educação matemática (UNESP), Professora, Universidade Federal de Pernambuco, Caruaru/PE/ Brasil.
} 
Keywords: Cartography. To become. Difference philosophy. Mathematical Formation. Subjectivity.

\section{Resumen}

Este trabajo presenta un extracto de las discusiones y observaciones de campo llevadas a cabo para la producción de datos de la disertación de maestría "ALICIA EN EL PAÍS DE LA DIFERENCIA: Una aventura para el profesor de matemáticas de los primeros años de la escuela primaria". El objetivo principal de los cuales era comprender las subjetividades presentes en el profesor de matemáticas de los primeros años de la escuela primaria. Un estudio resultante del método de mapeo de subjetividad, llevado a cabo durante la investigación de campo con maestros de una escuela pública en Jaboatão dos Guararapes - PE. Basado en la filosofía de diferencia de Deleuze y en la perspectiva de sujeto y sociedad defendida por Foucault para pensar sobre el maestro y sus subjetividades. Los resultados encontrados revelan al profesor como una materia compuesta de subjetividades, donde en una maraña de marcas, afectos y deseos resultantes de la trayectoria antropológica, los movimientos y el devenir, lo que impacta en la constitución de sí mismo que legitima las singularidades presentes en el proceso de enseñanza y aprendizaje matemático.

Palabras claves: Cartografía. Convertirse. Filosofía de la diferencia. Formación Matemática. Subjetividad.

\section{Introdução}

Enquanto sujeito/docentes imersos em uma historicidade dinâmica, um ser em devir, constituímos, desconstituímos e reconstituímos nossas subjetividades em um infido estado de mudança (TÁRTARO, 2016). Esses processos de subjetividades que perpassam os sujeitos professores, tornam a formação docente em matemática repleta de afetos e significados. Deleuze (2006) permite-nos pensar a diferença como uma agregação de forças que são derramadas no devir (movimento permanente de transformações), capazes de produzir novas subjetividades a partir dos encontros com o outro. Esses encontros permitem ao sujeito que de forma inusitada, ou não, construa e transforme sua subjetividade, portanto consideramos o devir como um processo contínuo e de transformações mútuas através das relações sociais vivenciadas.

Assim, trazemos esses argumentos para estruturar nosso pensamento sobre o devir professor, uma vez que, durante a docência desfazemos e refazemos nosso modo de agir e pensar por meio das constantes transformações que emergem das vivências sociais. Diante disso pensaremos os movimentos estabelecidos entre o professor dos Anos Iniciais e o saber matemático, pois acreditamos que diante dos múltiplos encontros com os saberes matemáticos presente no cotidiano, nas instituições acadêmicas e no ambiente escolar, múltiplos afetos brotam por meio de experiências vividas e marcas adquiridas. Um processo de subjetivar ou ser subjetivado, o sujeito professor constitui e desconstitui saberes de maneira ímpar. Portanto, o docente não apenas exterioriza seus conhecimentos, ele se transmite dando um sentido singular ao processo de ensino.

A aceitação do conceito de devir, torna possível pensar o sujeito aberto aos relacionamentos com o meio o qual está inserido e as forças que o atingem, uma entrega as imprevisibilidades presentes, são múltiplas possibilidade de agir diante dos encontros que realizam, a explosão de diferentes si. Esse pensamento nos permite aceitar as múltiplas formas de agir, pensar e desejar nos encontros realizados, contribuindo para a constituição de si. 
No território das produções acadêmicas, muito é pensado e produzido referente à Educação Matemática, entretanto, após visitar duas bases ${ }^{3}$ de dados referentes às pesquisas acadêmicas produzidas nacionalmente, vislumbramos uma escassez de trabalhos voltados para o processo de ensino e aprendizagem matemática na perspectiva da filosofia da diferença. Dessa forma, pensamos em cartografar as subjetividades presentes no devir professor de matemática dos Anos Iniciais do Ensino Fundamental, o que é o objetivo geral deste estudo. O qual buscamos alcançar a partir do seguintes objetivos específicos: i) Apresentar os conceitos de singularidades e subjetividades a luz da filosofia da diferença apresentada por Gilles Deleuze e Michel Foucault; ii) Compreender o devir docente a luz dos principais conceitos apresentados por Gilles Deleuze e Michel Foucault e iii) Descrever a partir da cartografia as subjetividades que perpassam o devir professor de matemática dos anos iniciais do ensino fundamental. Assim, ao alcançar os objetivos que fundamentam essa pesquisa buscamos reconhecer o professor como sujeito singular, constituído por subjetividades que são produzidas a partir dos processos históricos pelos quais eles perpassam.

\section{Desbravando a filosofia da diferença}

Ao adentrar pela filosofia da diferença, nos deparamos com palavras desconhecidas inicialmente ou que recebem outros significados estruturais - Conceitos que divergem de suas definições conhecidas - que causam certo desconforto. Como se os saberes presentes naquele momento não fossem suficientes para estabelecer conexões lógicas para compreender o que é apresentado. O que acontece pelo fato do sentido de um conceito estar relacionado com seu criador. Assim, qualquer conceito "[...] sempre tem uma história, embora a história se desdobre em ziguezague, embora cruze talvez outros problemas ou outros planos diferentes. Num conceito, há, no mais das vezes, pedaços ou componentes vindos de outros conceitos [...]" (DELEUZE; GUATTARI, 1992, p.29).

Para Gallo (2000) fazer filosofia é um trabalho intenso, que não se constitui por repetições de filósofos. Para ele, o papel principal da filosofia é criar conceitos.

Portanto, só se criam conceitos a partir dos problemas que nos são colocados. Criar conceitos de formação é produzir para si um plano de imanência. Dessa forma, um conceito de formação não se situa em determinado gênero ou espécie, mas sim nas composições de suas práticas (TÁRTARO, 2016, p.59).

O plano de imanência é o solo de produção dos conceitos, crescendo horizontalmente, o qual atribui sentido as multiplicidades e ao devir do conceito, estando diretamente interligados. Porém, diante dessa condição de dependência não podemos pensar no conceito e o plano de imanência com uniformidade. Ao pensar nos símbolos (letras) $X$ e $Y$, por exemplo, percebemos que eles habitam em múltiplos territórios e desempenham em cada um deles significados diferentes, de acordo com o plano que se encontram. Tomemos como exemplo o contexto das ciências biológicas o X e Y representam cromossomos sexuais, essenciais no estudo da determinação do sexo biológico dos humanos e em grande parte de mamíferos. Já no contexto da matemática, eles assumem múltiplos

\footnotetext{
${ }^{3}$ Associação Nacional de Pós-Graduação e Pesquisa em Educação (ANPED) eBiblioteca Digital de Teses e Dissertações (BDTD).
} 
significados, podendo ser utilizadas no plano cartesiano para representar um eixo de coordenadas, representar elementos de uma equação, uma função ou ainda representar um conjunto. Se pensarmos a partir da dimensão da língua portuguesa eles representam uma letra do sistema alfabético de escrita. Deste modo, observamos o quanto o contexto é relevante. Podemos então associar o plano de imanência como sendo as disciplinas mencionadas (o contexto), e os símbolos $X$ e $Y$ como conceitos criados diante de alguma problemática, logo cada plano/disciplina/contexto apresenta um sentido diferente para os mesmos elementos.

Nesse sentido, podemos dizer que o presente trabalho se movimentará dentro do plano de imanência da filosofia da Diferença, traçando conexões com o território educacional, desta forma é imprescindível compreender os conceitos que compõe o plano de imanência desta perspectiva filosófica. Na intenção de deslocá-los para a dimensão da educação. Assim, a filosofia da Diferença, à luz de Gilles Deleuze pode ser entendida como uma ferramenta que nos possibilita entender as singularidades presentes nos processos de constituição dos professores de matemática enquanto sujeitos subjetivos que transitam em um constante devir.

É através do rompimento da concepção lógica do sujeito que surge o conceito de filosofia da diferença, apresentada por Foucault, Deleuze e Guattari. O que esses autores nos apresentam como filosofia da diferença, seria uma filosofia do múltiplo, do singular, do devir, da alteridade, do subjetivo. A qual nos possibilita um olhar para as singularidades e multiplicidades dos sujeitos que compõe a sociedade. Peters (2000) considera que o sentido de multiplicidades expressa pelo conceito de diferença rompe com a dicotomia presente nos sistemas estruturados. Categorizando de forma excludente o que é verdadeiro ou falso, certo ou errado.

As multiplicidades são a própria realidade e não supõe nenhuma unidade, não entram em nenhuma totalidade e tampouco remetem a um sujeito. As subjetivações, as totalizações, as unificações são, ao contrário, processos que se produzem e aparecem nas multiplicidades. (DELEUZE; GUATTARI, 1995, p. 8).

Assim, os estudos sobre multiplicidades e singularidades do sujeito respingam no cenário educativo, visto que o campo educativo é composto por múltiplos sujeitos que de forma ímpar se fazem presente no modo de ensinar, aprender e agir. Os sujeitos são singulares na forma de pensar, agir, representar e transformar-se. Esse aspecto é a base que torna imprevisível o modo como cada sujeito interage e se refaz junto ao processo de ensino e aprendizagem matemática. Buscamos através do reconhecimento da Diferença nos estudos pós- estruturais, trazer novos olhares para pensa e falar de educação matemática, reconhecendo as diferenças e singularidades de cada sujeito diante desse processo. $\mathrm{O}$ que possibilita ser a educação algo imprevisível, pois é singular o modo que cada sujeito interage e se constitui, desconstitui e reagem as linhas as forças que the são perpassados.

\subsection{Sujeitos, subjetividade e Devir}

Ao se movimentar no pensamento Deleuziano, percebe-se um distanciamento entre a ideia de Sujeito e a de Homem, em favor do que seria um "Ser-devir", um princípio que parte da concepção de Subjetividade, que se resume a partir das forças constituídas nas diferentes formas de comunicações com o meio o qual habita. Logo, consideramos que o 
"Ser" sujeito se encontra em permanentes transformações, que surgem a partir da relação com o outro, portanto se faz necessário discutir os conceitos transversais às multiplicidades do "Ser" e a forma que se constitui.

Observa-se que Deleuze rompe a categoria sujeito e homem por acreditar e valorizar a ideia de subjetividade e assim também de multiplicidade. Para Lemos (2006), o sujeito é definido por sua multiplicidade, um arranjo das diferenças que livremente ligam e se religam continuamente, impossibilitando determinar as possibilidades do vir a ser. É a partir do múltiplo e da diferença que imprevisíveis movimentos podem acontecer.

\begin{abstract}
A força da multiplicidade e das intensidades com que se traçam mapas e linhas de fuga o constituem como nômade e, por isso mesmo, como aquele que não é apreendido. Deleuze põe em jogo a representação do sujeito e submete este aos devires, às intensidades e às forças que criam e permitem novas experiências do pensamento, o procedimento da desterritorialização como procedimento experimentativo de re-criações da "subjetividade" (MIRANDA, 2010, p. 268).
\end{abstract}

Mas, qual seria o conceito de sujeito na filosofia da Diferença? No que se refere às ideias trazidas por Deleuze, Foucault e Guattari o sujeito seria um todo composto de partes. E estas partes são constituídas e desconstituídas pelos sentidos atribuídos na interação com a sociedade, envolto aos processos históricos os quais foram submetidos. "[...] é ele a realidade glacial sobre o qual vão se formar estes aluviões, sedimentações, coagulação, dobramentos e assentamentos que compõem um organismo - e uma significação e um sujeito" (DELEUZE; GUATARRI, 2006, p. 20). Na percepção foucaultiana o sujeito é tido como possível de mudanças. Resultado da relação de poder que estabelece, os saberes que adquire, e as subjetivações que o compõe. Em Foucault (1969), encontramos a substituição da concepção de sujeito individual pelo sujeito transindividual, situando o sujeito em uma dimensão histórica e cultural, a qual torna suas atividades psíquicas e comportamentos repletos de significados. Mas, o que isso diz a respeito da educação matemática? Em sua tarefa de educar, o professor ao situar-se na sala de aula faz uso de diversos instrumentos, saberes e discursos em uma busca incessante de ensino.

Durante os processos de subjetivações que perpassam os sujeitos da educação, temos que o docente não apenas exterioriza seus conhecimentos como também se transmite, dando um sentindo singular ao processo. "A subjetividade não é uma posse, não é estática, mas sim algo que está em constante movimento e vai se construindo aos poucos de acordo com os encontros e desencontros vividos, que produzirão efeitos (reações) na pessoa que de alguma forma irá moldar sua maneira de viver" (QUEIROZ, 2015, p.64). Nessas condições, o sujeito é o resultado das relações contínuas do que lhe é subjetivo e singular e dos modos de subjetivações que o atravessa. Logo, "[...] os sujeitos poderiam ser compreendidos como limites de um movimento contínuo entre um dentro e um fora." (PEIXOTO JUNIOR, 1962, p. 52). Portanto não existe o "eu sou", pois estamos suscetíveis a transformações que podem ocorrer em qualquer instante, estando o sujeito em um estado inconcluso. Neste estado temos que o sujeito é composto de subjetividades, as quais surgem dos encontros com outros sujeitos, de acordo com o meio o qual está inserido.

Deste modo, entendemos que a partir do momento que o sujeito entra em contato e deixa-se subjetivar pelas linhas de força que o perpassam surgem novas concepções de ver o mundo, logo estamos em um constante devir. Para Deleuze e Guattari "Os devires não são 
fenômenos de imitação, nem de assimilação, mas de dupla captura, de evolução não paralela, núpcias entre dois reinos." (DELEUZE; PARNET, 1998, p.3). O que permite que as transformações originadas dos processos de subjetivações presentes nos infindos contatos entre os sujeitos, não podendo ser considerado como uma repetição, trazendo uma sensação de um eterno "sendo".

Os devires são rizomáticos, não cópias, não repetições, não têm início nem fim, apenas o interminável movimento de estar sendo, não se tornam nem vão se tornando, pois não têm um fim. $O$ tornar-se passa a ideia de que 0 movimento, em algum momento, para por ter alcançado seu objetivo, que é o de se tornar algo (QUEIROZ, 2015, p. 32).

O devir é algo contínuo, é o gerúndio de um verbo (sendo, fazendo, pensando, supondo...), pois tudo que permeia o universo segue em movimento e, ao tentar cessar esses contínuos fluxos, deixamos escapar as diferenças. São as linhas de forças que permeiam os processos de subjetivação que conduzem os sujeitos em suas transformações.

Devir não é certamente imitar, nem identificar-se; nem regredir-progredir; nem corresponder, instaurar relações correspondentes; nem produzir, produzir uma filiação, produzir por filiação. Devir é um verbo tendo toda sua consistência; ele não se reduz, ele não nos conduz a "parecer", nem "ser", nem "equivaler", nem "produzir" (DELEUZE; GUATARRI, 1997, p.19).

É através do emaranhado de linhas de forças que se ligam ao devir e orientam as direções a seguir, que nossa subjetividade é traçada continuadamente.

\subsection{O devir professor de matemática enquanto forma que se transforma}

Pensar o professor de matemática como sujeito em devir é uma representação que diverge da concepção que a sociedade estabeleceu para este profissional. Habitualmente, o professor que ministra aula de matemática é visto como alguém que domina os conteúdos, extremamente rígido, autoritário e de identidade conclusa e estática. Um imaginário que pode ter se construído ao longo dos anos à medida que a pessoa do professor era associada às características do objeto de estudo da disciplina.

Segundo Fiorentini e Lorenzato (2012), nas licenciaturas em matemática predominam a assimilação de conteúdos e domínios de técnicas. Essa preocupação por uma formação inicial lógica e conteudista, tem alimentado a imagem de um professor constituído e pronto, o que acaba não levando em consideração os processos históricos que o permeiam e suas subjetividades.

A filosofia da diferença rompe com esse pensamento, não enxergando o professor de matemática como sujeito de identidade associada à racionalização e padronização que opera na disciplina. Trabalhando assim em uma dimensão filosófica que nos oferece ferramentas teóricas capazes de nos revelar que o professor não é uma folha em branco ao entrar na graduação e que sai dela completo e preparado para lecionar. Pois, existe uma multiplicidade de linha de forças que agem em seu devir professor, alterando suas subjetividades, fazendo-o "fugir" do planejado.

Não podemos esquecer-nos da historicidade que compõe nosso devir, não há um estado pronto, não há subjetividades apagadas. Somos um estado inconcluso de existência. Somos resultado de dobras, de redobramentos, de dobras na dobra. Resultamos e 
expressamos uma forma que se transforma e continua infinitamente a mudar. Nessa busca incessante por compreender a maneira que o sujeito se constitui podemos pensar a partir do princípio do origami, a arte milenar de dar forma, a partir das idas e vindas de uma dobra. A partir dessas concepções compreendemos o sujeito enquanto ser flexível, onde na perspectiva Deleuziana a "[...] sua aparência reflete as dobras e redobras" (MIRANDA, 2010, p. 267), que realizam.

Da mesma forma que o origami é manuseado a fim de ser transformado em algo preestabelecido, assim também acontece com o sujeito, mas em contrapartida, o resultado final será imprevisível. Os processos de subjetivação procuram modelá-lo através das linhas de força que o perpassam, é o momento de permitir ou não que ela o transpasse.

Nesta perspectiva, o sujeito professor realiza mudanças que compõem sua singularidade, em uma constante produção de subjetividade. Se pensarmos na técnica do Origami, por exemplo, uma única forma inicial - um quadrado -é possível construir uma variedade de figuras, dependendo apenas das dobras. Semelhante acontece com os sujeitos em seu devir professor, em que se deparam compor diferentes forças que o transpassam ou não, fazendo-o agir de diferentes formas ao longo de sua vida docente.

Diante desses movimentos de transformações, somos marcados através das forças que nos afetam durante as interações que vamos realizando.

Ora, o que estou chamando de marcas são exatamente estes estados inéditos que se produzem em nosso corpo, a partir das composições que vamos vivendo. Cada um destes estados constitui uma diferença que instaura uma abertura para a criação de um novo corpo, o que significa que as marcas são sempre gênese de um devir (ROLNIK,1993, p.2).

As marcas são parte de um devir. É através das marcas que se torna possível traçar novos caminhos e novas visões de mudo. De um modo singular diante do que é vivenciado o sujeito vai compondo e (re) significando outras marcas. Percebemos que a marcas sempre gênese de um devir.

E assim vamos nos criando, engendrados por pontos de vista que não são nossos enquanto sujeitos, mas das marcas, daquilo em nós que se produz nas incessantes conexões que vamos fazendo. Em outras palavras, o sujeito engendra- se no devir: não é ele quem conduz, mas sim as marcas. (ROLNIK, 1993, p.3).

Partindo da compreensão de devir apresentada, percebemos que somos transformados a partir do momento que nos permitimos experienciar, pois estamos em um processo de continuo de relações com outros sujeitos, porém poucas nos marca, nos afeta e nos transforma.

\section{A cartografia como percurso metodológico}

Faz-se necessário que a metodologia escolhida aprecie uma educação que reconheça as subjetividades constituídas, desconstituídas e reconstituídas nos encontros com o meio e com a matemática, tal como as singularidades presentes nos diversos modos de se fazer professor. Frente uma cultura que tenta moldar as multiplicidades presentes nos processos de ensino e aprendizagem, exemplificada nas propostas de formações de professores a qual muitas vezes o docente é visto apenas como um profissional sem vida externa a sala de aula, 
ou uma tábua rasa em que os conteúdos são depositados para serem reproduzidos de igual maneira.

Assim, buscamos compreender o devir professor ao descrever as subjetividades, afetos e marcas constituídas nesses infindáveis movimentos de transformação. Observamos o professor em nossa pesquisa como um sujeito inacabado, composto por um emaranhado de linhas indissociáveis. Percebemos o ato de ensinar como algo único, específico de cada sujeito.

É através da aproximação com a filosofia que trazemos a cartografia apresentada por Gilles Deleuze e Félix Guattari (1995), como uma possibilidade outra de pensar e realizar pesquisas no âmbito da educação. Necessariamente, não estaríamos excluindo os demais processos metodológicos, ou afirmando que este seja melhor do que outro, mas, apresentado pesquisas em educação matemática numa perspectiva diferente por meio da filosofia. De modo a trazer um olhar sensível para as múltiplas questões presentes na educação, desapegando da visão objetiva e lógica que a matemática pura e aplicada propõe.

Apesar de utilizado na Geografia Física e na Geografia Humana, referindo-se à atividade de representar graficamente a superfície terrestre, e características da população de determinada região, é possível também encontrar o conceito de cartografia nas obras de Gilles Deleuze e Félix Guattari (1995). Inspirados em Michel Foucault em seu livro $A$ arqueologia do saber, eles apresentam um novo sentido para o termo cartografia, ao o deslocar para o campo filosófico. Deste modo:

Gallo (2003, p.10), alinhado ao pensamento de Deleuze, justifica esse deslocamento como a arte de criar conceito, pois, para ele "A criação de conceitos é, também, um ato de roubar conceitos dos outros; segundo ele, o roubo é criativo, pois sempre transformamos aquilo que nos apropriamos". Assim, ao roubar o conceito de cartografia da geografia, de forma recriada, o principal sentido de traçar linhas permanece relacionado ao pensamento filosófico. Dessa forma, enquanto os geógrafos representam paisagens a partir de traçados (linhas), os quais dão forma aos mapas, os cartógrafos nas pesquisas filosóficas representam paisagens psicossociais, cenários históricos em que somos constituídos como sujeitos. Criam-se novos mundos possíveis de exteriorizar subjetividades, não visíveis em um mundo anterior, dando voz aos afetos que vibram por passagem (ROLNIK, 1987).

A partir dos questionamentos levantados, percebemos que o caminho de quem valoriza a diferença dever ser receptível às mudanças que encontramos durante o trajeto. A sensibilidade do cartógrafo é a bússola que lhe guia a cada encontro, mostrando os novos rumos a serem tomados. Segundo Rolnik (1989), a cartografia como metodologia de pesquisa é composta de caminhos abertos com múltiplas saídas, no qual o pesquisador pode entrar e sair a qualquer instante. "No movimento de sua pesquisa, o cartógrafo encontra-se com coisas, corpos, nações, paixões, algo que o inquieta e que convém; mapeia movimentos de territorialização das linhas; indica movimentos de desterritorialização." (OLIVEIRA; PARAísO, 2012, p.171).

Dessa forma, cartografar é construir mapas, e não decalque, pois o decalque consiste em reproduzir algo já feito de forma idêntica, não permite rupturas, os traços são copias e não constituições múltiplas de novos territórios, os quais não haviam sido habitados antes. "Um mapa tem múltiplas entradas contrariamente ao decalque que volta sempre "ao mesmo" (DELEUZE; GUATTARI, 1995, p. 22).

De acordo com Deleuze e Guattari (1995), somos perpassados por múltiplas linhas com padrões, ritmo e natureza distintas, que constantemente se encontram compondo 
nosso mapa. Portanto, o papel do cartógrafo é o de captar as forças que movem essas linhas, compreendendo as diversas faces de um determinado fenômeno. Ainda nesta mesma perspectiva conceitual, o ato de cartografar seria similar ao movimento de desembaraçar um novelo de linha, linhas de subjetivação, forças, fuga, ruptura e resistência que operam o dispositivo ${ }^{4}$, de forma rizomática.

Através da utilização da cartografia é possível mapear subjetividades, ao adentrar por diversos dispositivos que perpassam os sujeitos, se aprofundando através das múltiplas dimensões que o compõe "[...] em cima, embaixo e por todos os lados" (ROLNIK, 1989, p.67). Procuramos olhar além da ponta do iceberg, mergulhando abaixo da superfície do mar, o que nos permite sentir as águas que vibram por passagens, assim como avistar as camadas não contempladas quando é visto através da superfície, descobrir algo não escondido, visualizando o que está fora do olhar (DELEUZE, 2005). Portanto, o cartógrafo busca trilhar por territórios existências ${ }^{5}$ e "mergulhar na geografia dos afetos e, ao mesmo tempo, inventar pontes para fazer sua travessia: pontes de linguagem." (ROLNIK, 1989, p.67).

Fala-se então de um fluxo contínuo de vibrações nos encontros entre o cartógrafo e o que está sendo cartografado, capturando intensos afetos que constitui campo existencial em que ambos estão envolvidos É deste modo que observamos e conversamos com os/as professores/professoras de matemática em busca de perceber elementos envolvidos em seu devir professor.

A mesma autora defende que o perfil do cartógrafo é definido pela sensibilidade que ele deixa florescer em seu trabalho, os deslocamentos que realiza diante do que é apresentado. $O$ valor que atribui às produções de subjetividade, movimentos do desejo ao acompanhar processos e devires. É sua sensibilidade que permite entender as linhas de forças que perpassam o território que está imerso, para ele entender e dar voz aos afetos, subjetividades e marcas que buscam expressão. Não existe intenção de explicar ou buscar soluções para um determinado fato. O seu trabalho depende do valor que se é atribuído ao que o "[...] corpo vibrátil capta no ar". (ROLNIK, 1997, p. 4).

Com o intuito de conseguir abrir passagem para os afetos, para as subjetividades, sentir, captar e desemaranhar as múltiplas linhas de força que permeiam o território existencial do que está sendo cartografado. Em nossa pesquisa teremos como instrumentos metodológicos os mapas narrativos ${ }^{6}$, questionários, entrevistas e observações de aula. A escolha vai depender do olhar sensível, é através dos sentimentos que afloram que os instrumentos vão sendo escolhidos e utilizados. Assim estaremos em uma constate busca de elementos, pistas, fatos e índices para alimentar nosso espírito investigativo, o qual proporciona a construção desta cartografia.

Sentimos que por meio da cartografia é possível desemaranhar e tornar visíveis os desejos, as marcas, as linhas de subjetivações que perpassaram o sujeito durante os diversos

\footnotetext{
${ }^{4}$ Foucault (2000) define como dispositivo o conjunto heterogêneo de discursos, instituições, organizações arquitetônicas, decisões regulamentares, leis, medidas administrativas etc. Com objetivo de disciplinar, capturar e controlar. Posteriormente aprofundaremos o conceito de dispositivo apresentado por Michel Foucault, deslocando-o para o cenário educativo.

${ }^{5}$ Deleuze e Guattari (2012), define como território existencial o espaço onde os sentidos, as expressões, as marcas são apresentadas, através de um processo histórico.

6 Para Bovo (2011), os mapas narrativos são combinações entre desenhos, narrações e entrevistas, um movimento capaz de desemaranhar linhas de forças e apresentar as marcas que compõe os sujeitos.
} 
encontros com a matemática. Portanto, acreditamos que será possível chegarmos ao complexo composto de forças, sentidos e afetos que mesclam as subjetividades agindo no devir professor. Criando assim uma ponte que perpasse o vazio que existe entre o que o sujeito sente, pensa e expressa (SILVA et al.,2013). Lançando um olhar sensível à educação matemática, a qual não pode ser vista apenas com foco na lógica racional, deve considerar as emoções e as subjetividades, pois embora se trate de uma disciplina exata, o processo de ensino aprendizagem acontece a partir de uma relação que se faz entre sujeitos.

\section{Desemaranhando as linhas de subjetividades}

Nosso campo de pesquisa é uma Escola Municipal de Jaboatão dos Guararapes, a qual oferece apenas Educação Fundamental para os anos iniciais, A escolha dos participantes da pesquisa foi feita de modo a estabelecer conexão com o objeto de estudo, assim os sujeitos são professoras concursadas dos anos iniciais do Ensino Fundamental, graduadas em licenciatura em pedagogia.

Dessa forma, pretendemos aqui situar nossos sujeitos de pesquisas no tempo e espaço através das narrativas pessoais de quatro professoras. Nesse sentido, se torna parte essencial do nosso trabalho reviver de um modo sutil os processos de individuação, pois "[...] o ser em processo de individuação é aquele no qual uma resolução aparece pela sua repartição em fases, isto é, a partir de uma 'incompatibilidade inicial rica em potenciais'" (BARROS; KASTRUP, 2012, p. 23, grifo do autor). Adentrar os planos das experiências em que a realidade se comunica caminhado transversalmente as dimensões que permeiam os sujeitos "[...] os grupos, as instituições e as organizações são redes de inter-relações, isto é, relações entre relações" (BARROS; KASTRUP, 2012, p. 28).

Ainda segundo os autores, é preciso que o cartógrafo mergulhe na realidade do outro, permitindo-se conhecer os processos onde o devir professor acontece, acompanhando os movimentos que as linhas realizam para traçar e compor a realidade dos planos, pois ao acompanhar os processos de constituições e adentrar em outros dispositivos é possível conhecer a realidade.

É importante trazer, que, as professoras cartografadas lecionam a disciplina de matemática, pois as Diretrizes Curriculares Nacionais para o Ensino Fundamental anos Iniciais e Finais ${ }^{7}$ (Resolução CNE/CEB no 7/2010) apresenta a matemática como uma área do conhecimento importante na construção de um pensamento lógico, crítico e reflexivo. Dessa forma, o currículo deve contemplar o trabalho com a disciplina.

De acordo com a instrução normativa da secretaria de educação de Jaboatão dos Guararapes no 3/ 2010, através de um alinhamento com as Diretrizes Curriculares Nacionais estabelece a carga horária semanal referente à área de conhecimento matemático para o Ensino Fundamental Anos Iniciais e Finais.

\subsection{Sobre a professora Ana}

Uma garota muito tímida, na escola era reservada e tinha poucos amigos. Filha do meio dos setes filhos de José e Maria, a timidez não permitia que Ana se envolvesse de forma ativa durante as aulas escolares. Ser filha de um vigilante e de uma dona de casa que

7As Diretrizes Curriculares Nacionais para o Ensino Fundamental anos Iniciais é um documento orientador que norteia a construção do currículo da educação nacional. 
estudaram apenas até o ensino fundamental dificultava o acompanhamento das atividades escolares por seus pais. Porém apesar das dificuldades, os sete filhos eram constantemente incentivados a estudar, sua mãe definia um horário de estudo que era acompanhado pelos irmãos mais velhos. Seus pais reservavam o período da noite para os estudos, como fazer lições de casa e estudar para as provas. Sempre estudou em escola pública, Ana lembra que nesse período, a precariedade do ensino, a falta de professores, a rigidez do ensino de alguns professores na área de exatas, foram fatores que contribuíram para o desenvolvimento das dificuldades de alguns conteúdos matemáticos. $O$ ensino precário da educação, principalmente na disciplina de matemática levou Ana a enfrentar algumas dificuldades no período do vestibular, pois apareciam assuntos nunca vistos no ensino médio, principalmente os conteúdos voltados para figuras geométricas, análise combinatória e probabilidade. Nesse caso errava questões, porque não sabia resolvê-las.

Inicialmente Ana pretendia cursas administração, porém ao perceber que o curso de administração não seria uma boa escolha por possuir muitos cálculos e contas, ela tenta encontrar uma saída traçando uma linha de fuga, escolher um curso que não tivesse muitos cálculos, surge o desejo de escapar. Após realizar as provas do vestibular Ana consegue entrar no curso de Pedagogia. Apesar do ensino escolar sem reprovações, durante a graduação na Universidade Federal de Pernambuco ela enfrente alguns desafios, além das dificuldades apresentadas pelas lacunas da educação básica. Precisava conciliar os estudos com o estagio na prefeitura do Recife no contra turno. Pois precisava da bolsa para arcar com as despesas na Universidade, como cópia de material, compra de livros e também vale transporte. Em alguns momentos não tinha um bom desempenho nas provas por não ter dinheiro para adquirir material e estudar para provas.

Hoje Ana é Pedagoga especializada em gestão da cultura organizacional, leciona há nove anos. Porém, antes de iniciar na atual escola como servidora pública, trabalhou no administrativo de uma empresa. Atualmente, mora com seus pais e não tem filhos, o que a mesma afirma proporcionar uma maior disponibilidade para fazer seu planejamento e preparar as aulas do 40 ano durante a semana.

A sala de aula matemática de Ana é composta por 16 alunos com idade média de 10 anos, todos sentados em fileiras de modo tradicional. Observando a parte física notamos que em suas paredes existiam muitos cartazes de diversas disciplinas e datas comemorativas, e dois da disciplina matemática, que apresentavam o tratamento de informações e gráficos coloridos. Ana inicia sua aula utilizando o quadro branco, usa um relógio de papel para explicar as horas com uma série de perguntas referentes às posições dos ponteiros, apesar de levar um relógio de papel para tornar a aula mais lúdica, realizava de modo mecânico perguntas diretas e objetivas, sem nenhuma problematização do conteúdo, o que associamos com sua visão objetiva da matemática.

Posicionada na frente do quadro explica o conteúdo, porém uma grande parte da sala não acompanha, existe muita conversa paralela, como se o discurso expresso não lhes capturasse. Mesmo diante do barulho, dos alunos entrando e saindo da sala, Ana pouco para a aula para chamar atenção deles ou saber o que estava acontecendo. Muito calma e deforma mansa às vezes pedia silêncio, justificando que estão sendo observados. Tal posicionamento nos leva a refletir sobre a possibilidade da presença de alguém a observar a atuação do professor poder influência no modo como ele se comporta, são novas forças que podem influenciar o processo de sujeitamento ou de resistência da docente observada. 
Cartógrafa: Eu observei que eles ficam dispersos durante a aula, e que não há muita participação.

Ana: Eles sempre são assim, não são interessados. Porém, creio que necessito de um planejamento de conteúdo voltado para realidade de aprendizagem de cada aluno, pois muitas vezes o aluno não assimila com facilidade o assunto do livro, e o conhecimento matemático que possuo não é suficiente para desenvolver melhores práticas.

Cartógrafa: Ana, você poderia usar esses lápis e canetas para desenhar ou escrever o que representa a matemática para você?

Figura 1 - Mapa narrativo sobre o que representa a Matemática para a professora Ana

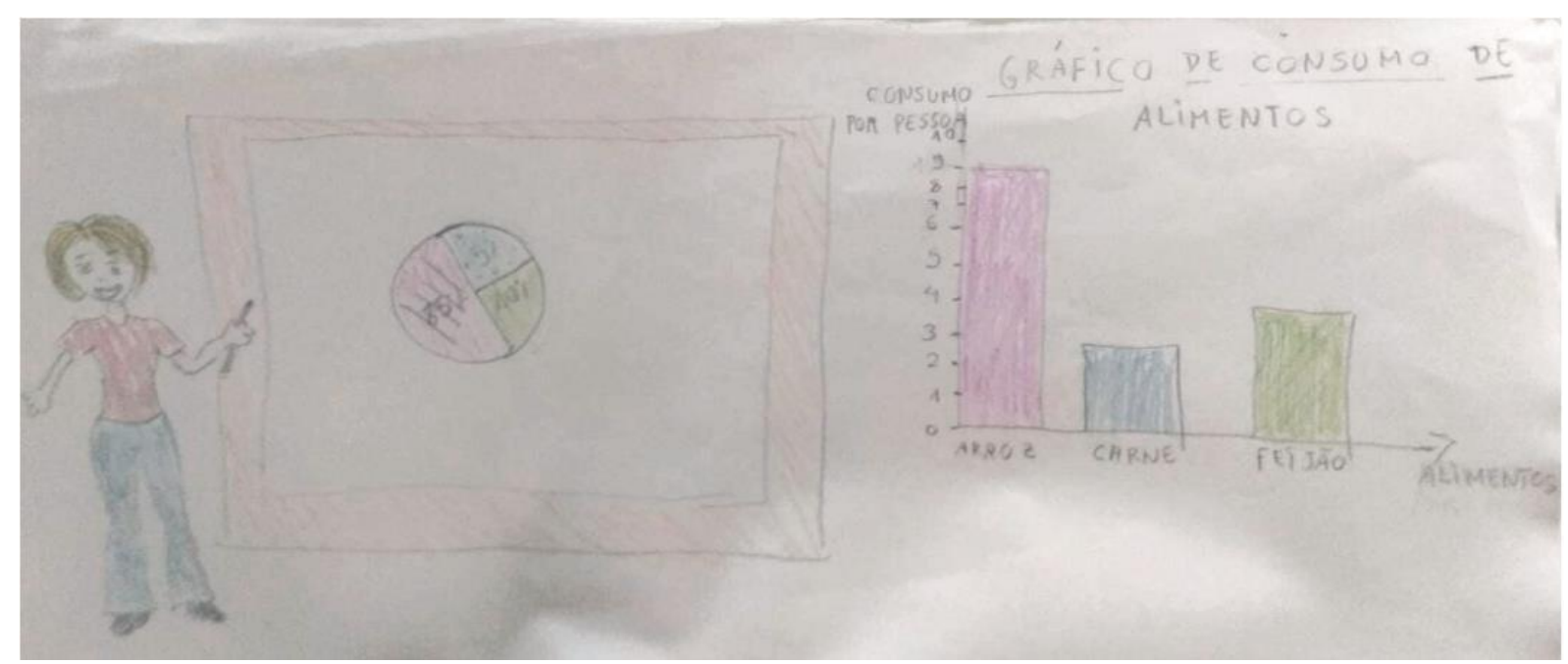

Fonte: A autora, 2019.

Cartógrafa: Essa professora é você?

Ana: Não, esse desenho se refere à professora da graduação, como não tinha conhecimento com tratamento de informações durante o ensino fundamental e médio eu tive muita dificuldade em entender na graduação. Com essa professora devido à didática dela, eu consegui aprender. Eu desenhei a professora fazendo uma referência a minha professora anterior no ensino médio, pois ela era bem rígida eu tinha muito medo dela e devido a essa rigidez no ensino eu não compreendia o conteúdo, acredito que tenho um bloqueio. Assim, na universidade eu encontrei uma professora totalmente aberta diferente do que eu tinha vivenciado antes.

(Diálogo entre a cartografa e a professora Ana, 2019).

\subsection{Sobre a professora Joana}

Era uma menina muito comportada e estudiosa, assim thes descrevia os antigos professores. Seus pais, sempre frequentavam as reuniões escolares e voltavam para casa com muitos elogios referentes ao comportamento da filha. Joana era a mais nova de uma família de três filhos, pai motorista e mãe dona de casa, ambos não conseguiram finalizar o Ensino Fundamental. Seus pais não eram presentes na rotina de estudo, suamãe ficava com a responsabilidade de levar e buscar na escola, de cobrar que eu organizasse a bolsa para o dia seguinte e orientar sobre a importância de estudar. Participava dos plantões pedagógicos e elogiava os resultados positivos.

Joana sempre estudou em escola pública e no fundamental II ficou com muito déficit nas aulas de matemática. $\mathrm{Na} 60$ série passou praticamente o ano todo sem professor e no 
ano seguinte teve muita dificuldade de acompanhar o conteúdo. A professora teve que voltar em muitos conteúdos para poder introduzir os novos. Um dos principais que não tinha visto era equação e lembra que a princípio teve muita dificuldade, mas depois se apropriou dos conteúdos como a professora deste ano era muito boa conseguiu aprender e desenvolver afinidade com a matemática. Porém, muitos assuntos não foram dados e são lacunas que a acompanham até hoje. No ensino médio teve três excelentes professores, um deles gostava de fazer desafios no quadro com questões matemática, ela gostava muito porque sempre conseguia resolver os desafios rapidamente.

Durante as aulas de Matemática, Joana era sempre muito atenta ao que era explicado pelos professores, às vezes não entendia o que era explicado, porém se esforçava para não reprovar e não ficar em recuperação, visto que era uma exigência dos pais que os filhos tivessem boas notas. Podemos pensar que o fato de Joana muitas vezes não receber ajuda em casa, fizesse com que ela buscasse ao máximo compreender o que a professora ensina, uma vez que sabia que era a única fonte que tinha para compreender a matéria. Quando seus pais compreendiam o assunto, ensinavam-na de um modo simples, igualmente como eles utilizavam no cotidiano. $O$ que por vezes Isso facilitou sua compreensão quando estava na escola.

Atualmente Joana é formada em Pedagogia e Mestre em educação na área de linguagem. Casada, com dois filhos pequenos optou em trabalhar em apenas um turno para acompanhar o desenvolvimento dos filhos. Por causa das atribuições de mãe e dona de casa, o tempo se torna apertado para planejar as alunas, quando é possível ela planeja no final de semana. Considera o trabalho como professora um hobby, pois é algo que ela tem prazer de realizar.

Ao adentrar a sala de aula matemática de Joana, composta por 20 alunos do 5o ano, é possível perceber que existe por parte da professora um domínio em sala, pois os alunos estão todos sentados e em silêncio. Nas paredes da sala existem alguns cartazes referentes a trabalhos de algumas disciplinas, mas nada relacionado à matemática.

Antes de iniciar a aula, a professora com um "ar" de preocupação e um certo desespero, o motivo era a situação dos alunos com baixos índices em matemática. Afirmando que, a maioria dos alunos tem muitas dificuldades com matemática, poucos realizam as atividades de casa. Foi realizada uma prova sobre divisão, a grande maioria saiu mal, não souberam interpretar os problemas matemáticos e resolver os quatros operações, principalmente divisão. Existe uma cobrança por parte da gestão, por causa das provas externas, mas ela afirmou não saber o que fazer. Pois, acredita já ter feito tudo, às vezes a gestão faz cobranças sobre o desempenho, mas não existe uma resposta de como realizar. Notamos que aparentemente existe por parte de Joana certa insatisfação com o processo de ensino e aprendizagem matemática.

Depois do desabafo, a professora inicia aula, o conteúdo de hoje é sistema de medida, de modo bem tradicional a professora utiliza o quadro branco para ministrar sua aula, atenta às dúvidas dos alunos pergunta constantemente se eles estão compreendendo, o assunto é trabalho de uma forma bem superficial com alguns desenhos no quadro, em alguns momentos ela pergunta - Se tem alguém que ainda não entendeu, eu posso fazer alguns dos meus desenhos maravilhosos.

Cartógrafa: Ao trabalhar matemática você se sente segura, ou existe algum desconforto na sua prática docente. 
Joana: Eu sinto muita falta de uma formação na área de matemática, porque eu tenho muitas lacunas na minha formação enquanto aluno do ensino fundamental e médio, quando eu cheguei no pré-vestibular senti muitas dificuldades de varias lacunas que foram bem trabalhadas, na graduação também só sabia uma coisa bem rasteira, então eu tenho varias lacunas que não foram bem trabalhados na área de matemática e sinto muita dificuldade de trabalhar com os alunos, muitas mesmo! Já teve época que eu quase não trabalhava matemática, por exemplo, quando era no ciclo de alfabetização sempre dava uma ênfase na alfabetização enquanto na matemática eu sempre dava o mínimo. Hoje com uma fase de mais conteúdos tem os eixos que se tem que trabalhar com ele, os assuntos do livro aí você vai "desenrolando", meu suporte é o livro do professor, eu não venho dar aula de matemática sem o livro, porque têm algumas questões que eu tenho insegurança aí eu tenho que recorrer a ele. Ano passado eu fui ler as orientações do professor para trabalhar fração porque eu não sabia trabalhar algumas partes. Eu tenho muita dificuldade, eu não sei se é pela falta de formação que não tem muito estímulo as metodologias, ou devido minha deficiência no conteúdo. Por exemplo, quando eu fui preparar a aula de hoje eu iria trazer uma balança para eles manusear e testar, mas pela falta de conhecimento eu fico com medo de gerar alguma situação que você não vai saber explicar direito para os alunos, então não adianta eu trazer uma aula bem diferente se eu não der conta das duvidas que possam aparecer. Você percebeu que hoje eu só trabalhei com litros e mililitros, eu poderia estender para as unidades de medidas, mas eles talvez não entendessem, e ficaria também mais difícil para eu explicar isso para eles.

Cartógrafa: Gostaria que você utilizasse estas canetas para desenhar como você vê a educação matemática.

Figura 1 - Mapa narrativo sobre o que representa a Matemática para a professora Joana

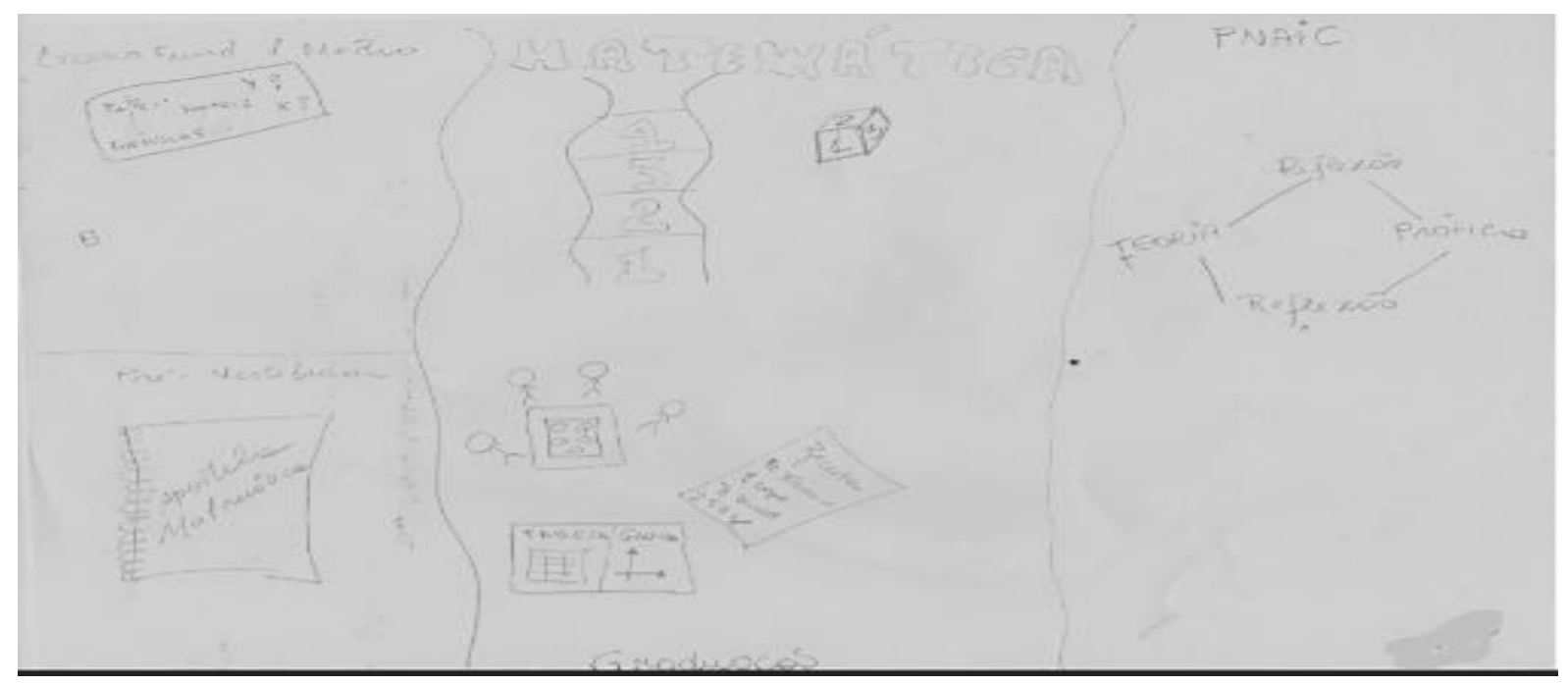

Fonte: A autora, 2019.

Cartógrafa: Joana poderia explicar porque diante de tantas canetas coloridas você preferiu usar um lápis. E o que significa o desenho para você?

Joana:Para mim a matemática ainda é muito preto no branco! No primeiro momento eu procurei trazer o que foi a matemática para mim no ensino médio, muitas formulas $e$ cálculos, muita P.A e P.G, eram uma coisa bem mecânica eu me dava bem nessas aulas porque eu memorizava tudo, inclusive eu tive um professor que quando eu perguntava $o$ porquê e ele fala que era assim. Era muito decore a fórmula e faça, sem discussão nenhuma. No segundo momento foi quando eu entrei no pré-vestibular, aí eu percebi que tinha varias 
lacunas de conteúdo que eu não tinha aprendido no fundamental e médio, como era de escola pública faltava muito professor. No pré-vestibular que eu vim conhecer outros conteúdos, principalmente geometria. A última parte foi quando eu entrei na faculdade, só tive duas disciplinas de metodologia de ensino de matemática, a primeira era uma professora que gostava muito de brincar, de fazer coisas lúdicas, quando acabou a disciplina percebemos que não tinha aprendido conteúdo. Ai só na segunda professora que trabalhamos mais conteúdo. Eu aprendi pouca coisa com essas disciplinas no curso de pedagogia, não me deram base para trabalhar na escola, só quando eu fiz o PNAIC que eu aprendi muita coisa que necessitava na sala de aula, como eu já estava lecionando o que eu aprendia lá aplicava com aos alunos, isso que deu uma clareada maior no meu trabalho em sala de aula.

(Diálogo entre a cartografa e a professora Joana, 2019).

\subsection{Sobre a professora Maria}

A professora Maria, considerava-se uma aluna "mediana" por não conseguir muitas vezes acompanhar os conteúdos da disciplina de matemática, em geral, durante as aulas era atenta e participativa, mas muitas vezes na aula de matemática como não entendia o que era explicado procurava pensar e fazer outras coisas. Pois, tinha dificuldade em entender os conteúdos matemáticos, no ensino fundamental ( 60 ano), fiquei em recuperação apenas nesta disciplina. Fiz aulas de reforço e conseguir recuperar. No ensino médio as dificuldades de Maria se intensificaram o que resultou em uma reprovação.

Sua mãe finalizou o ensino médio e exercia a função de bancária, sempre foi muito boa em matemática, mas nunca teve muita paciência para ensina e também não tinha muito tempo. Mesmo assim, me auxiliava nas lições, tanto nos assuntos vistos no dia letivo, quanto os assuntos das revisões. Sempre foi estimulada a estudar, aprendi a ler com quatro anos de idade, porém a matemática nunca foi meu forte, estudava mais para cumprir o "protocolo" e não porque gostava da disciplina.

Diante das dificuldades encontradas na escolarização, Maria se matricula no curso pedagogia, para lecionar de forma interessante e agradável aos educandos, coisa que ela nunca teve enquanto aluna do ensino fundamental, poder fazer diferença na vida dos seus estudantes. Atualmente, Maria é professora do 4 음 ano, uma turma com aproximadamente 20 alunos consideravelmente bem disciplinados. Ao expor muitos trabalhos realizados pelos alunos nas paredes da sala, sentimos falta de representações de atividades matemáticas, despertando uma sensação de que a disciplina não morava ali. Um lugar extremante agradável por sua organização, planejamento das atividades. Escrevia diariamente suas rotinas diárias no canto esquerdo do quadro branco.

Cartógrafa: como acontece sua intervenção com os alunos durante a aula?

Maria: Os alunos não querem, eu faço minha parte, mas quando o aluno não quer, eu não tenho muito que fazer. Enquanto professora, fico muito triste porque quero que todos cresçam. É difícil para mim, percebo que na aula de matemática é mais difícil, grande número de desinteressados, em outras aulas eu utilizo matérias do dia a dia deles para relacionarem, assim eles interagem mais.

Cartógrafa: Você afirmou que fica triste porque os alunos não acompanham, mas tem mais alguma coisa que desperta esse sentimento em relação ao processo de ensino $e$ aprendizagem matemática?

Maria: Sinto-me frustrada em relação a minha postura como professora de matemática, pois no ensino médio e fundamental tive problemas com a matemática. Meu foco, o que eu me identifico é com o português. Se minha educação matemática básica no tempo de escola 
tivesse sido melhor eu poderia me envolver mais com os alunos, sentiria mais segurança para auxiliá-los melhor.

Cartógrafa: Maria, gostaria que desenhasse esses sentidos sobre a matemática que você me relatou agora. O que a disciplina representa para você?

Figura 1 - Mapa narrativo sobre o que representa a Matemática para a professora Ana

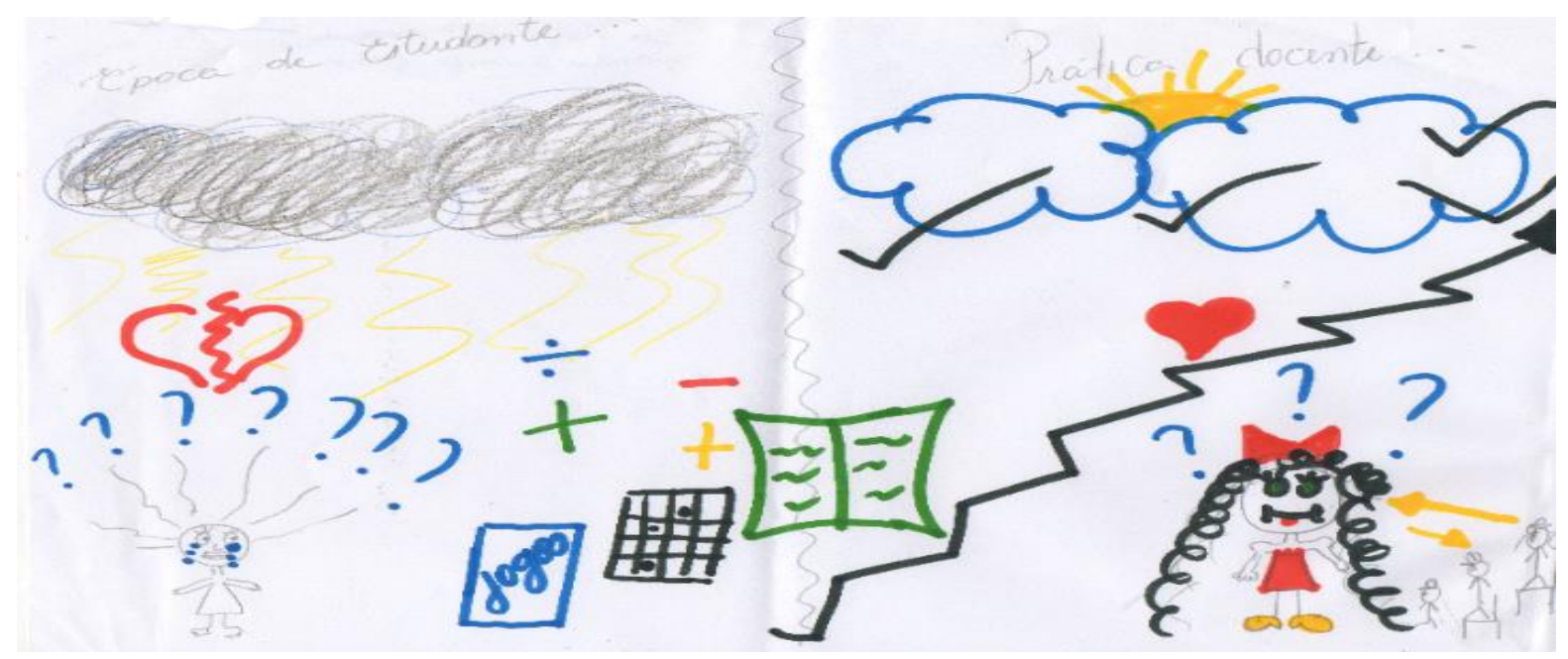

Fonte: A autora, 2019.

Cartógrafa: Maria poderia me explicar seu desenho.

Maria: Aqui foi o seguinte, na época de estudante de ensino Fundamental 1, fundamental 2, até no ensino médio a gente fica cheia de incerteza né! De certa forma é de partir o coração, porque você não sabe como realizar as atividades matemática, os exercícios. Então você fica meio que perdido, você não tem uma base, você não tem professores que fazem com que você goste da disciplina, então você fica triste. No meu caso eu ficava muito apreensiva, muito nervosa. E, meus pais, por mais que eles tivessem uma formação em ensino superior, eles não tinham tanto tempo pra sentar comigo e me ensinar. Aí essa passagem aqui, é da época de estudante de ensino médio para a universidade e hoje na prática docente, eu já pude ver, já tive outra visão da matemática, fui apresentada aos jogos, como a gente pode ensinar através de jogos e isso ajudou muito na minha profissão e ajuda até hoje, na minha prática docente. Então, de todas aquelas dúvidas, continuo tendo dúvidas sim, não foi um milagre, da água para o vinho não.

(Diálogo entre a cartografa e a professora Maria, 2019).

\subsection{Sobre a professora Sara}

Sara cresceu em uma cidade pequena no interior de Pernambuco, sempre foi muito comportada e estudiosa. Dessa forma, seus pais não se preocuparam com essa parte de educação, porque ela e sua irmã sempre tiravam boas notas, e gostavam muito de ir à escola. Quando surgia alguma dúvida procurava sua mãe, pois como ela tinha concluído o ensino médio em geral conseguia explicar, o que era muito difícil para seu pai por apenas ter estudo até a 4a série. Diante das dificuldades financeiras que enfrentou na infância e adolescência, precisou por volta dos 13 anos trabalhar em uma bomboniere para ajudar os pais, com o dinheiro ajudava a mãe em casa, muito prendada e inteligente também fazia bordados para ganhar um "trocado" extra. 
Durante o ensino escolar não tinha dificuldades, devido a estudar em escolas do interior de Pernambuco aos assuntos básicos e exigia mais a "decoreba", sentia falta de uma base melhor, assuntos com um maior grau de dificuldade nas disciplinas de matemática, até mesmo física e química. No ensino médio as lacunas começaram aparecer, principalmente na área de exatas, quando começou a estudar pra o vestibular, porque o ensino no interior era muito fraco, muito repetitivo, e aí atrapalhou muito no seu processo de escolha de uma profissão, porque eu acabei optando por um curso que fosse menos concorrido pra poder tentar passar numa universidade pública, já que meus pais não tinham condições de pagar uma universidade particular. Mas quando eu estava na adolescência eu queria muito ser advogada. Só que terminei indo pra área da pedagogia, muito pela questão de sair do interior pra tentar oportunidades, pensava que por minha família não tinha condições de manter uma faculdade e me manter aqui no recife sozinho. Assim, com pedagogia teria mais facilidade de conseguir um estágio.

Cartografa: Poderia fazer um desenho utilizando essas canetas sobre a educação matemática para você?

Figura 1 - Mapa narrativo sobre o que representa a Matemática para a professora Ana

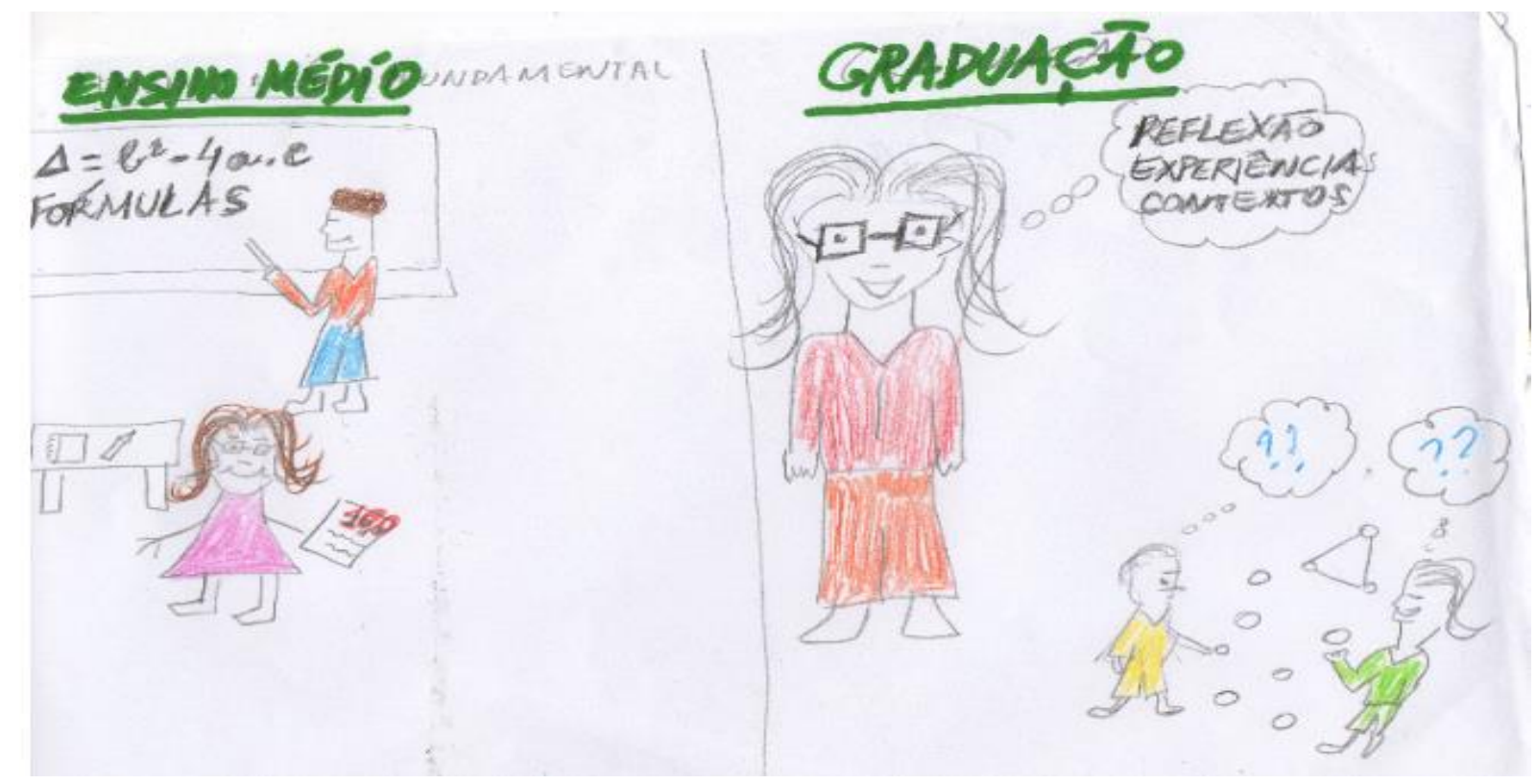

Fonte: A autora, 2019.

Cartografa: Você poderia explicar seu desenho?

Sara: Falei pra tu, no decorrer da minha fala que no ensino fundamental eu sempre fui uma excelente aluna em todas as matérias, porque não existia um trabalho muito de reflexão, de contextualização, então tudo era muito repetição. Eu conseguia fazer tudo porque era tudo repetição. Então, tinha essa questão das mesmas questões, as mesmas questões matemáticas, só mudava os números, era muito descontextualizado, aí eu coloquei até essa fórmula pra mostrar aqui, que era muita repetição. E na graduação eu me vi em novo cenário, onde eu tinha que tentar buscar uma outra forma de estudar, porque era muito disciplinada na repetição, na memorização. E quando eu chego à graduação eu tenho que buscar me esforçar mais pra poder alcançar o que eles estavam me cobrando dentro da graduação.

(Diálogo entre a cartografa e a professora Sara, 2019). 


\section{Considerações finais}

Os processos de subjetivação pelo qual os sujeitos atravessam podem capturar o sujeito professor de forma que, através dos seus discursos e posicionamento em sala de aula seja repleto de subjetividades e marcas que impactam de forma positiva ou negativa no modo lecionam.

Percebemos que ao fazer seus desenhos as professoras visitam suas memórias e constroem a imagem que guardaram sobre o momento em que estavam na posição de alunas para agora pensar a sua postura enquanto professoras. As situações possíveis de causar marcas no devir das professoras, discutidas a partir da filosofia da diferença são expostas nos lugares de memória apresentados.

Ao cartografar as professoras, desembaralhamos múltiplas linhas de subjetividades, as quais nos possibilitaram perceber que o fazer professora de matemática está permeado de subjetividades, constituídas durante os encontros com a disciplina enquanto estudante, sendo afetado e marcado pelo modo que a matemática foi vivenciada historicamente, uma construção de si repleta de devir.

Os sujeitos trazem diversas marcas de perdas, fracassos, dificuldades, sofrimento e dor. "Nossos corpos carregam consigo marcas das conexões que vamos fazendo vida afora, com pessoas, livros, discos, roupas, filmes, bichos, paisagens, que potencialmente nos expandem em direções imprevistas" (PRECIOSA, 2011, p.3). Algumas marcas são (re) significadas outras adormecidas, outras estão ativas aprisionando o modo de agir e pensar. Segundo Gaparotto (2010), é através das experiências que as marcas se instalam em nosso corpo, sua potencialidade de voltar a reverberar é maior quando é atraída por ambientes e movimentos semelhante ao que lhe constituiu.

A filosofia da diferença serve como lente para visualizar os acontecimentos que perpassam a educação matemática, reconhecendo o professor como sujeito singular, repleto de fragmentos de devir, reconhecendo que de maneira ímpar eles estabelecem o modo como agem no ambiente escolar. Tendo como plano de fundo as experiências vivenciadas e as subjetividades que o constitui. Percebe-se com a postura das professoras encontradas que os movimentos que realizam em sala de aula são devires.

Ao observamos as diferentes professoras e modos de ensinar presentes no contexto escolar que percorremos, juntamente com o emaranhado de linhas, que traçam os territórios existências dos docentes, percebemos a diferença com que elas se relacionam com o processo educativo, as quais resultam do trajeto antropológico de cada uma. Percebe-se a presença das singularidades no modo de ensinar. Em relação ao ensino da matemática, foi observado que a disciplina sempre foi vista com certa aversão para a maior parte das professoras, sendo um obstáculo, ou algo extremamente difícil e chato. Desta forma, as dificuldades com a disciplina durante o período escolar e a graduação constituíram marcas, que trazem certo desassossego e insegurança ao processo de ensino e aprendizagem da matemática.

Não é apenas a professora Joana e Ana, são uma multiplicidade de linhas que compõe as singularidades dos sujeitos, uma agregação de marcas, traços, subjetividades e sentidos que afetam o devir, revelando-se no modo que se apresentam em sala de aula. Um reconhecimento do professor da diferença como, sujeito que aprende, desaprende, ensina, se compõe, descompõe, cria, afeta, é afetado, marca, é marcado, territorializa, desterritorializa e reterritorializa 
Assim, sentimos que as salas de aulas matemáticas estão repletas de ações que refletem as especificidades de cada sujeito. $O$ devir professor de matemática é movido por todas as etapas que as professoras vivenciam, sua vida escolar, seu ambiente familiar e o processo de formação durante a graduação, fabricaram marcas que impactam nas subjetividades das professoras observadas. Seu devir acontece até mesmo em sua sala de aula, pois enquanto atuam como professoras realizam trocas com os estudantes, as quais podem refletir na prática e na pessoa que são.

\section{Referências}

BRASIL. Conselho Nacional de Educação; Câmara de Educação Básica. Resolução no 7, de 14 de dezembro de 2010. Fixa Diretrizes Curriculares Nacionais para o Ensino Fundamental de 9 (nove) anos. Diário Oficial da União, Brasília, 15 de dezembro de 2010, Seção 1, p. 34. Disponível em: http://portal.mec.gov.br/dmdocuments/rceb007_10.pdf. Acesso em: 24 Ago. 2019.

BARROS, G.; MUNARI, S.; ABRAMOWICZ, A. Educação, cultura e subjetividade: Deleuze e a Diferença, Revista Eletrônica de Educação, v.11, n.1, p.108-124, jan./maio, 2017.

DELEUZE, G. Diferença e Repetição. Rio de Janeiro: Graal, 2006.

DELEUZE, G. Foucault. Tradução: C. S. Martins. São Paulo: Brasiliense. 2005.

DELEUZE, G. O que é um dispositivo? In: Michel Foucault, filósofo. Barcelona:

Gedisa, 1990.

DELEUZE, G.; GUATTARI, F. O que é a filosofia? Tradução Bento Prado Jr. e Alberto Alonso Muñoz. São Paulo: Editora 34, 1992.

DELEUZE, G.; GUATTARI, F. Mil Platôs: do capitalismo e esquizofrenia. Rio de Janeiro: Ed. 34, 1995a. V. 1.

DELEUZE, G.; GUATTARI, F. Mil Platôs: Capitalismo e Esquizofrenia. Tradução: SuelyRolnik. V.4. São Paulo: Ed. 34, 1997

DELEUZE, G.; PARNET, C. Diálogos. Tradução Eloisa Araújo Ribeiro. São Paulo: Escuta, 1998.

FIORENTINI, D. LORENZATO, S. Investigação em Educação Matemática: percursos teóricos e metodológicos. 3 ed. Campinas: Autores Associados, 2012. Coleção formação de professores

FOUCAULT, M. O que é um autor? (1969) In: Ditos e Escritos - Estética: literatura e pintura; música e cinema. Rio de Janeiro: Forense Universitária, 2006.

GASPAROTTO, G. C. F. Alfabetização Matemática: Cartografando as Narrativas de Alguns Alunos na Série Final do Ensino Fundamental. 2010. 248f. Dissertação (Mestrado em Educação Matemática) Instituto de Geociências e Ciências Exatas, Universidade Estadual Paulista, Rio Claro, 2010.

GALLO, S. Deleuze e a Educação. Belo Horizonte: Autêntica. 2003.

GALLO, S. O Que é Filosofia Da Educação: anotações a Partir de Deleuze e Guattari. Perspectiva. Florianópolis, v. 18, n.34, pag. 49-68, julho/dez. 2000.

JABOATÃO DOS GUARARAPES. Instrução Normativa n. 03 de 12 de dezembro de 2015. Estabelece critérios para distribuição de carga horária e regulamenta o trabalho docente de formação coletivaTDFC dos professores da rede Municipal do Jaboatão dos Guararapes.

LEMOS, F. Diferença e educação: um diálogo com Hélio Rebello Cardoso Jr.Artifícios, Pará, v.1, n.2, p. 1-11, dez/2011. Disponível em: 
https://pt.scribd.com/document/244403480/Entrevista-Deleuze-e-a-filosofia-da-diferencapdf. Acesso em 10 de setembro 2018.

MIRANDA, W. A filosofia da diferença em Deleuze e Heidegger. Revista Ítaca, n.15, p. 250-271, Rio de Janeiro 2010. Disponível em: https://revistas.ufri.br/index.php/Itaca/article/view/265. Acesso em: 02 Nov. 2018.

OLIVEIRA, Thiago Ranniery Moreira.; PARAÍsO, Marlucy Alves. Mapas, dança, desenhos: a cartografia como método de pesquisa em Educação. Pro-posições, v.23, n.3, set./dez. 2012, p. 159-178. Disponível em: https://doi.org/10.1590/S0103-73072012000300010. Acesso em: 04 Nov. 2018 PEIXOTO JUNIOR, C.A. Singularidade e subjetivação: ensaios sobre clínica e cultura. Rio de Janeiro. 7 Letras: Editora PUC-Rio, 2008. 206p.

PETERS, M. Pós-estruturalismo e filosofia da diferença: uma introdução. Belo Horizonte: Autêntica, 2000.

PRECIOSA, R. Pensar o texto acadêmico como Produção de Subjetividade: anotações preliminares. Inclui bibliografia. In: Colóquio de Moda, 07, 2011, 08 p. Minas Gerais. Anais... Juiz de Fora: ISSN, I $982-0941$.

QUEIROZ, S. M. Movimentos que permeiam o devir professor de matemática de alguns licenciandos. Rio Claro, 2015. 206 f.

ROLNIK, S. Cartografia sentimental: transformações contemporâneas do desejo. SãoPaulo: Estação Liberdade, 1989.

ROLNIK,S. Uma insolita viagem a subjetividade - Fronteiras com a ética e com a cultura. In: Daniel S. Lins (org.) Cultura e Subjetividade: Saberes nômades. Campinas (SP): Papirus, 1997. PP.25-34.

ROLNIK, S. Pensamento, Corpo e Devir - uma perspectiva ético/estética/política no trabalho acadêmico In: Cadernos de Subjetividade. PUC/SP, set./fev, p 241-244.1993.

ROLNIK, S. Cartografia ou de como pensar com o corpo vibrátil, 1989.

SILVA, M. T. et al. Mapas e cartografia em educação matemática. In: XI Encontro Nacional de Educação Matemática (ENEM), 07, 2013, Curitiba. Anais... Parana: SBEM, 2005, artigos, p. do XI Encontro Nacional de Educação Matemática - ISSN 2178-034X. Disponível em:http://enem2013.pucpr.br/2013/07/19/anais-do-xi-enem/ Acesso em: 24 Nov 2018.

TÁRTARO, T. F. Ex Docente: Invenções do devir-guerreiro no professor de Matemática. Rio Claro, 2016. $178 \mathrm{f}$. 